Article

\title{
Characterization of Antifungal Natural Products Isolated from Endophytic Fungi of Finger Millet (Eleusine coracana)
}

\author{
Walaa Kamel Mousa ${ }^{1,2}$, Adrian L. Schwan ${ }^{3}$ and Manish N. Raizada ${ }^{1, *}$ \\ 1 Department of Plant Agriculture, University of Guelph, Guelph, ON N1G 2W1, Canada; \\ wmoatey@uoguelph.ca \\ 2 Department of Pharmacognosy, Mansoura University, Mansoura 35516, Egypt \\ 3 Department of Chemistry, University of Guelph, Guelph, ON N1G 2W1, Canada; schwan@uoguelph.ca \\ * Correspondence: raizada@uoguelph.ca; Tel.: +1-519-824-4120 (ext. 53396); Fax: +1-519-763-8933
}

Academic Editor: Derek J. McPhee

Received: 13 July 2016; Accepted: 27 August 2016; Published: 3 September 2016

\begin{abstract}
Finger millet is an ancient African-Indian crop that is resistant to many pathogens including the fungus, Fusarium graminearum. We previously reported the first isolation of putative fungal endophytes from finger millet and showed that the crude extracts of four strains had anti-Fusarium activity. However, active compounds were isolated from only one strain. The objectives of this study were to confirm the endophytic lifestyle of the three remaining anti-Fusarium isolates, to identify the major underlying antifungal compounds, and to initially characterize the mode(s) of action of each compound. Results of confocal microscopy and a plant disease assay were consistent with the three fungal strains behaving as endophytes. Using bio-assay guided fractionation and spectroscopic structural elucidation, three anti-Fusarium secondary metabolites were purified and characterized. These molecules were not previously reported to derive from fungi nor have antifungal activity. The purified antifungal compounds were: 5-hydroxy $2(3 \mathrm{H})$-benzofuranone, dehydrocostus lactone (guaianolide sesquiterpene lactone), and harpagoside (an iridoide glycoside). Light microscopy and vitality staining were used to visualize the in vitro interactions between each compound and Fusarium; the results suggested a mixed fungicidal/fungistatic mode of action. We conclude that finger millet possesses fungal endophytes that can synthesize anti-fungal compounds not previously reported as bio-fungicides against F. graminearum.
\end{abstract}

Keywords: finger millet; Fusarium sp.; endophyte; fungus; Penicillium sp.; 5-hydroxy 2(3H)-benzofuranone; dehydrocostus lactone; harpagoside

\section{Introduction}

Finger millet (Eleusine coracana) is an ancient cereal crop widely grown by subsistence farmers in Africa and India. Finger millet was domesticated in Ethiopia and Uganda at 5000 BC and then reached India by $3000 \mathrm{BC}$ [1]. Unlike other related cereals, finger millet is well known for its ability to tolerate stress conditions and to resist many pathogens, including Fusarium graminearum [2-5]. F. graminearum is a serious fungal pathogen that causes Fusarium Head Blight (FHB) in wheat and Gibberella Ear Rot (GER) in corn [6]. Both diseases result in catastrophic losses in grain yield and are associated with mycotoxin accumulation in grains [7]. Fusarium sp. are ancient fungi that have been dated to 8.8 mya in Africa [8], the same continent where finger millet was domesticated.

We hypothesized that the potential long-term co-evolution between finger millet and Fusarium sp. may not only have placed selection pressure on the genome of finger millet but also on its associated microbiome. Specifically, we hypothesized that finger millet may host endophytes that confer 
resistance to F. graminearum. Endophytes have been reported to help their host plants to combat pathogens $[2,9,10]$.
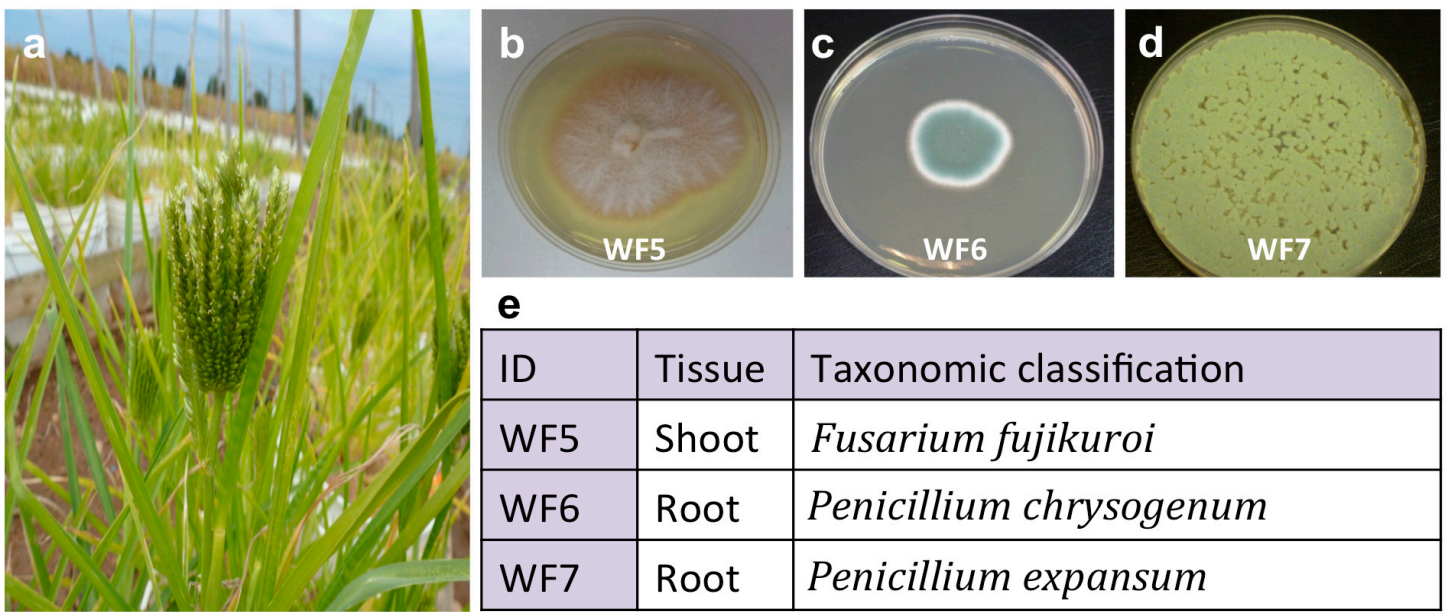

e
\begin{tabular}{|l|l|l|}
\hline ID & Tissue & Taxonomic classification \\
\hline WF5 & Shoot & Fusarium fujikuroi \\
\hline WF6 & Root & Penicillium chrysogenum \\
\hline WF7 & Root & Penicillium expansum \\
\hline
\end{tabular}
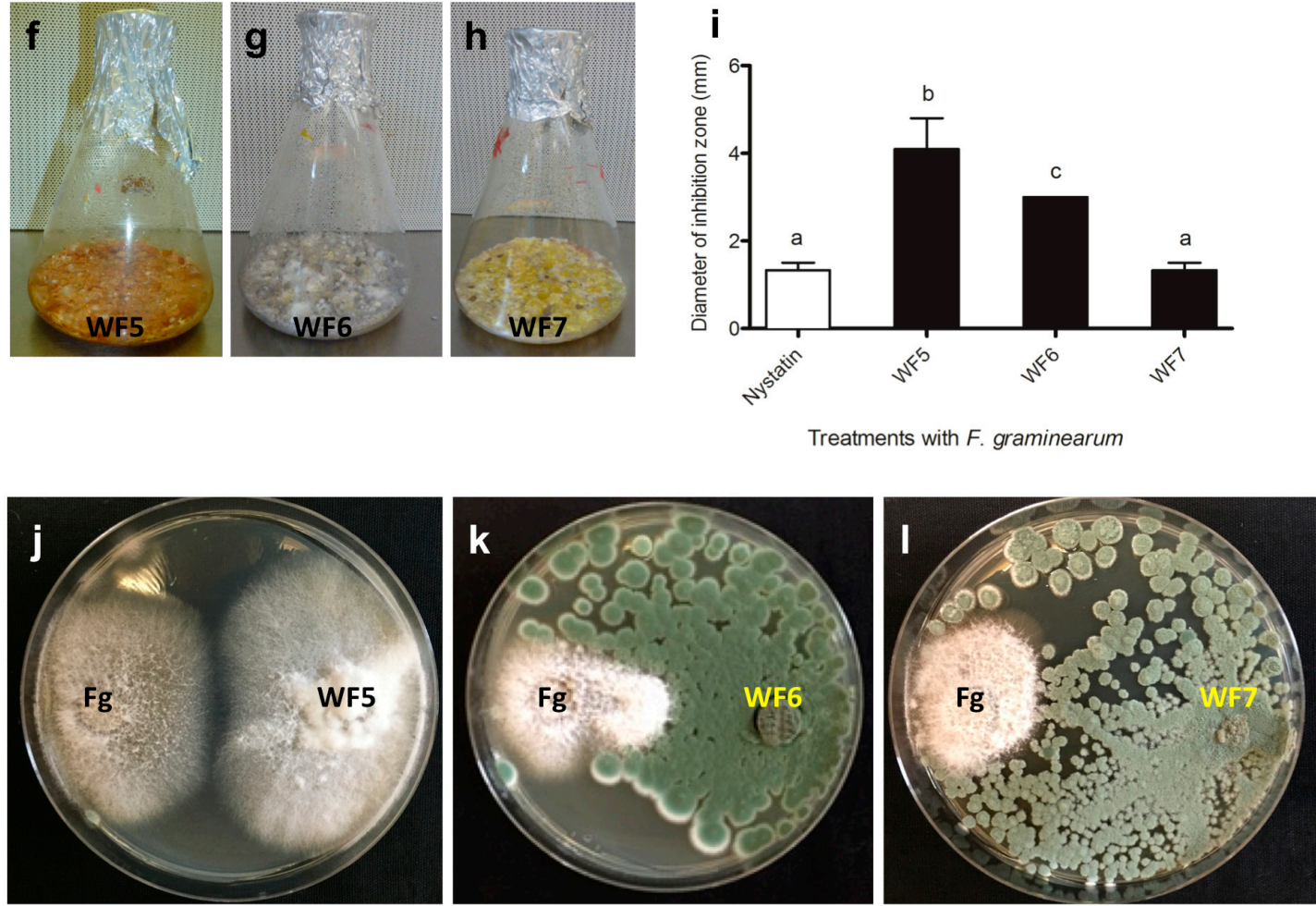

Figure 1. Characterization of the putative fungal endophytes previously isolated from finger millet and the antifungal activity of their extracts. (a) Picture of a finger millet plant; (b-d) Pictures of fungal endophytes WF4, WF5 and WF7 isolated from finger millet, respectively; (e) Predicted fungal endophyte nomenclatures, alongside the corresponding plant tissue from which they were isolated and best BLAST match taxonomic identification based on $18 \mathrm{~S}$ rDNA sequencing; (f-h) Example of each endophyte fermented on rice medium as indicated; (i) Quantification of the effects of each endophyte extract $(250 \mathrm{mg} / \mathrm{mL})$ on the growth of $F$. graminearum compared to the fungicide nystatin $(10 \mu \mathrm{g} / \mathrm{mL})$ (diameter of inhibition zone in $\mathrm{mm}, n=3)$; (j-1) Representative images illustrating the results of co-incubation of each endophytic fungus with $F$. graminearum in vitro.

Consistent with our hypothesis, in a previous study, we reported the isolation of four putative fungal endophytes (strains WF4-7) from finger millet and showed that their extracts had anti-fungal 
activity against F. graminearum [2]. Only one of these endophytes, Phoma sp. strain WF4, was analyzed in detail including isolation of the underlying anti-Fusarium compounds. Of the remaining strains, WF6 and WF7 (Penicillium sp.) were isolated from finger millet roots, while WF5 (Fusarium sp.) was isolated from shoots (Figure 1) [2]. The crude culture extracts of each strain inhibited the growth of F. graminearum (Figure 1) [2]. The objectives of this study were to confirm the endophytic behaviour of the three remaining, putative, anti-Fusarium fungal endophytes, to identify the underlying major antifungal compounds and to study the mode of action of each pure compound.

\section{Results}

\subsection{Confirming the Endophytic Behaviour of the Putative Fungal Endophytes}

To confirm the endophytic behaviour of the isolated finger millet fungi, two experiments were undertaken.

\subsubsection{Plant Pathogenicity Assay}

Seedlings of finger millet were co-incubated with each putative fungal endophyte or with a known pathogen of finger millet, Alternaria alternata. The seedlings inoculated with the pathogen developed disease symptoms including black roots and leaf spots and reduction in plant length (Figure 2a), compared to control seedlings that received the buffer only (Figure 2b). However, none of the putative fungal endophytes showed statistically significant disease symptoms on finger millet seedlings compared to the pathogen control (Figure 2c-g).
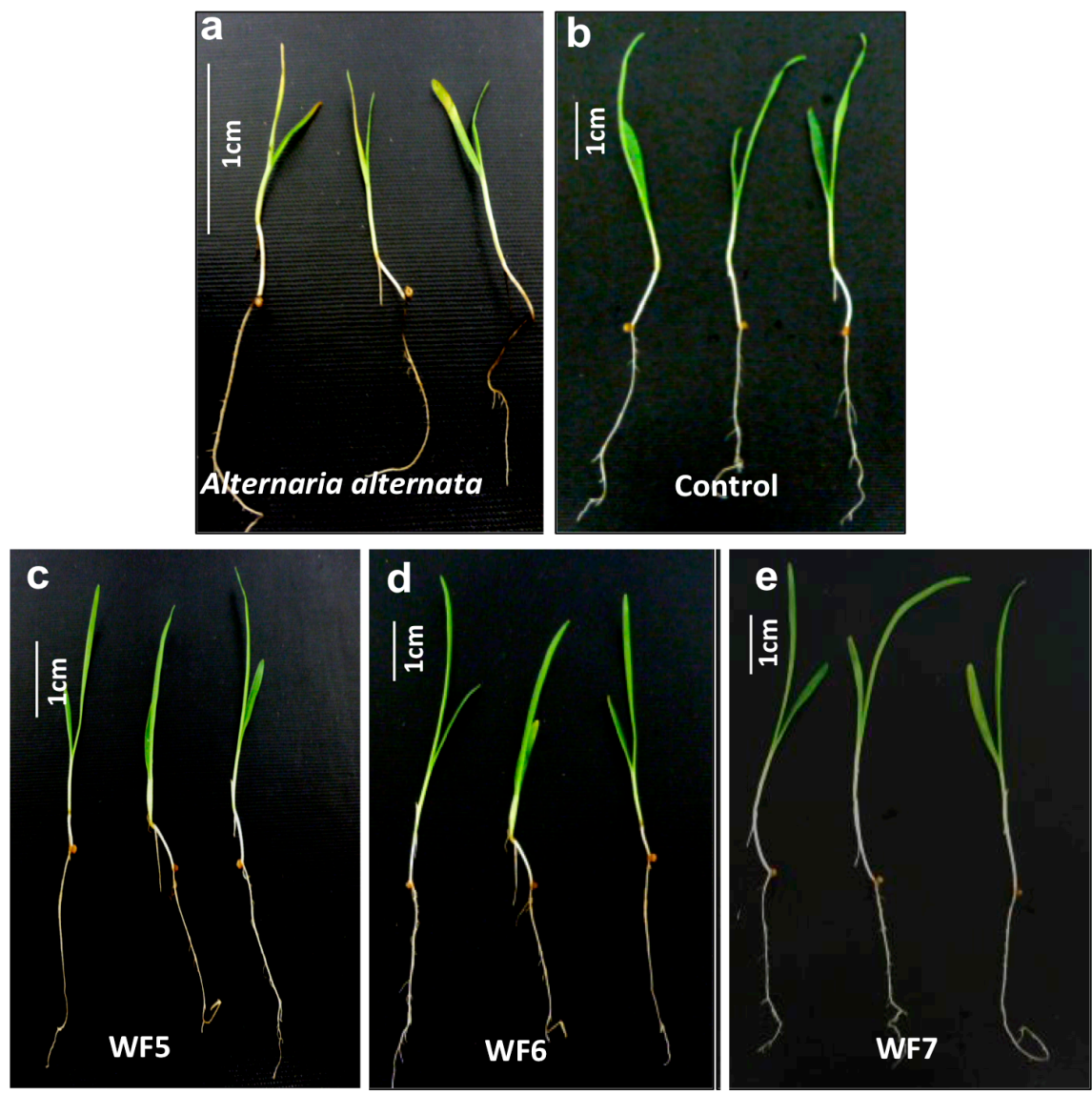

Figure 2. Cont. 

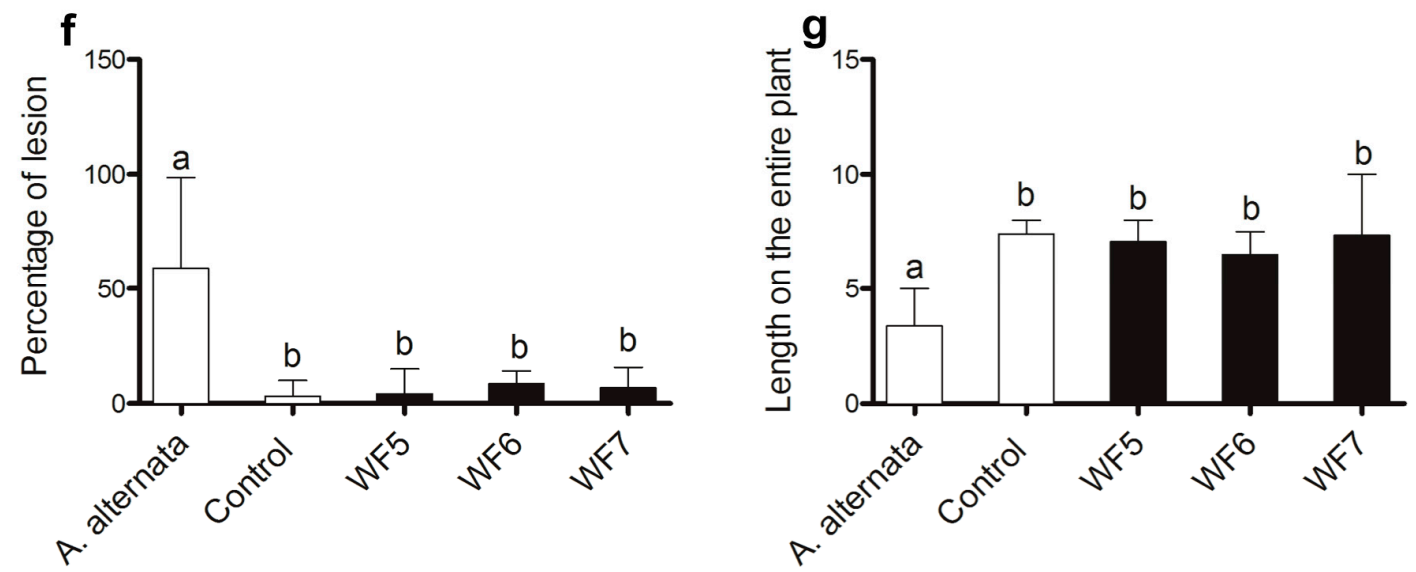

Figure 2. Plant pathogenicity assay of each putative endophyte following inoculation onto finger millet. (a) Representative picture showing the effect of the known pathogen Alternaria alternata on finger millet seedlings (positive control); (b) Representative picture showing the effect of buffer on finger millet seedlings (negative control); (c-e) Representative pictures showing the effect of the each putative fungal endophyte on finger millet seedlings as indicated; (f) Quantification of the percentage of lesions caused by each fungus or the pathogen Alternaria alternata compared to the control using Assess software; (g) Quantification of the total length of finger millet seedlings inoculated with each endophytic fungus or the pathogen Alternaria alternata compared to the control. For both (f) and (g), letters that are different from one another indicate that their means are statistically different (Mann-Whitney $t$-test, $p \leq 0.05$ ).

The whiskers indicate the standard error of the mean.

\subsubsection{Root Colonization Assay}

To test the ability of each endophyte to colonize the internal tissues of finger millet roots, confocal microscopy imaging was conducted. Seedlings inoculated with the buffer only (control) showed no observable fungal growth inside the tissues (Figure $3 a, b$ ). At the early post-inoculation time point used, most of the fungal hyphae were observed on the rhizoplane, however each of the fungi was visualized to initiate colonization of the epidermal and sub-epidermal layers of finger millet roots, providing further support that they are endophytes of finger millet (Figure $3 c-h$ ).
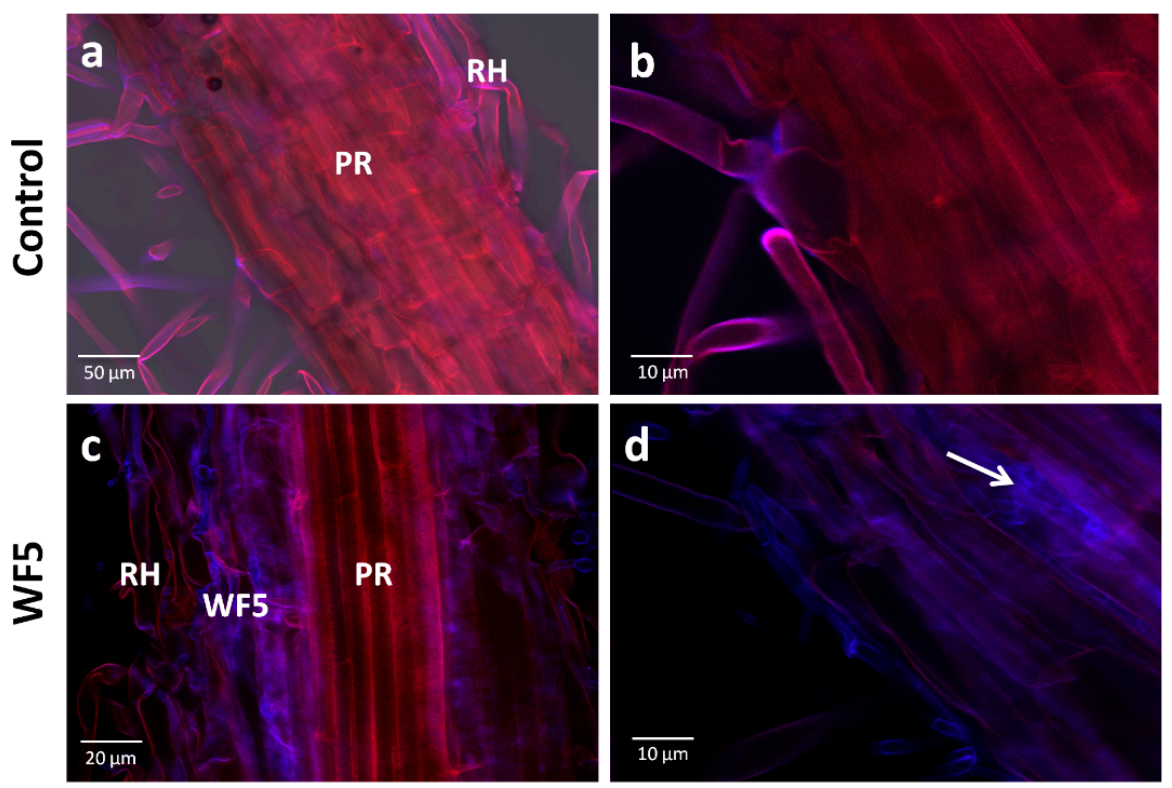

Figure 3. Cont. 

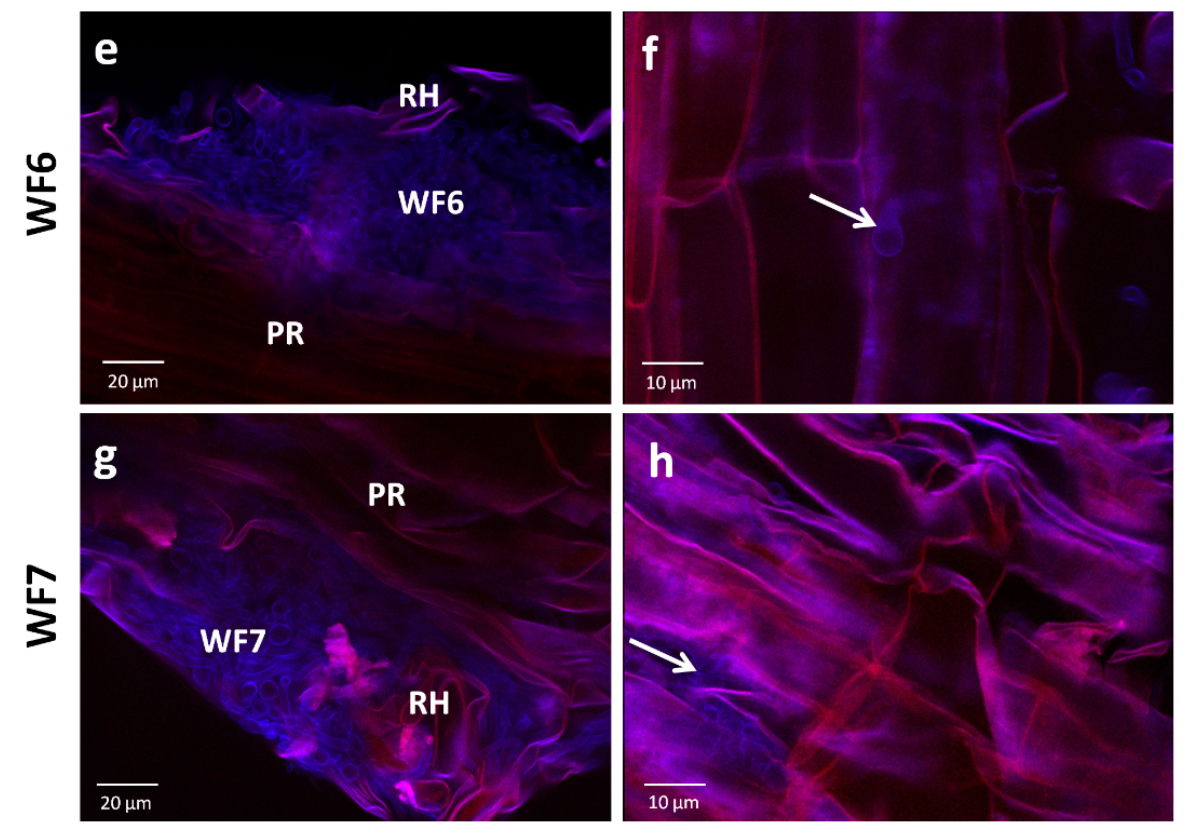

Figure 3. Test for the ability of the putative fungal endophytes to colonize finger millet roots using confocal scanning laser microscopy. (a-b) Representative pictures of root tissues inoculated with the buffer control; (c-h) Representative pictures of root tissues inoculated with each putative fungal endophyte as indicated. Fungi fluoresce purple-blue due to staining with calcofluor. Plant tissues appear red due to auto-fluorescence. White arrows point to fungi inside the tissues. Abbreviations: PR, primary root; $\mathrm{RH}$, root hair.

\subsection{Bio-Assay Guided Purification and Structural Elucidation of Anti-Fusarium Compounds}

Bio-assay guided purification was conducted to isolate the active anti-fungal compounds from each endophyte extract. Three active anti-Fusarium compounds were purified (Figure 4). The diameter of zones of growth inhibition of F. graminearum were 2, 2.5 and $1.5 \mathrm{~cm}$ for compounds 1, 2 and 3, respectively. The minimum inhibitory concentration (MIC) for compounds $\mathbf{1}-\mathbf{3}$ were 31.25, 250.00 and $31.25 \mu \mathrm{g} / \mathrm{mL}$, respectively. The three compounds were subjected to further spectroscopic structure elucidation. Results corresponding to each compound are shown separately below. 1D- and 2D-NMR spectra for these three compounds are presented (Figures S1-S15).

\subsection{Structural Elucidation of the Isolated Antifungal Compounds}

\subsubsection{Compound $\mathbf{1}$ (Isolated from Fungus WF5)}

Compound 1 (molecular formula $\mathrm{C}_{8} \mathrm{H}_{6} \mathrm{O}_{3}$ ) was eluted with hexane-ethyl acetate (90:10) as a white amorphous powder, with an Rf value of 0.46 , and further moved as a single band in hexane-ethyl acetate (85:15), with an $\mathrm{Rf}$ of 0.58 . The yield of compound 1 was $50 \mathrm{mg}$ from $3 \mathrm{~g}$ of total extract. IR: 3320, 1762, 1604, 1241, 1077, $948 \mathrm{~cm}^{-1} .{ }^{1} \mathrm{H}-\mathrm{NMR}(600 \mathrm{MHz}, \mathrm{DMSO}): 3.83(2 \mathrm{H}, \mathrm{s}, \mathrm{H}-3), 6.65(1 \mathrm{H}, \mathrm{dd}, J=8.6$, $1.6 \mathrm{~Hz}, \mathrm{H}-6), 6.75(1 \mathrm{H}, \mathrm{d}, J=1.6 \mathrm{~Hz}, \mathrm{H}-4), 6.95(1 \mathrm{H}, \mathrm{d}, J=8.6 \mathrm{~Hz}, \mathrm{H}-7), 9.32(1 \mathrm{H}, \mathrm{s}, \mathrm{Ar}-\mathrm{OH}) .{ }^{13} \mathrm{C}-\mathrm{NMR}$ (150 MHz, DMSO): 175 (C-2), 153.9 (C-8), 146.7 (C-5), 125.1 (C-9), 114.2 (C-4), 111.8 (C-6), 110.5 (C-7), 33.3 (C-3). Comparing spectral data (Figures S1-S5) with a previous reference [11], the compound was confirmed as 5-hydroxy 2(3H)-benzofuranone (Figure 4a).

\subsubsection{Compound 2 (Isolated from Fungus WF6)}

Compound 2 (molecular formula $\mathrm{C}_{15} \mathrm{H}_{18} \mathrm{O}_{2}$ ) was eluted from the hexane-ethyl acetate (50:50) fraction as a colorless solid. The compound was then purified by preparative TLC using a solvent mixture of hexane-ethyl acetate (30:70), with an Rf value of 0.73 . The yield of compound 2 was $10 \mathrm{mg}$ 
from $3 \mathrm{~g}$ total extract. The IR and 1D-NMR data were as follows: IR: 2934, 1765, 1257, 1146, $998 \mathrm{~cm}^{-1}$. ${ }^{1} \mathrm{H}-\mathrm{NMR}\left(600 \mathrm{MHz}, \mathrm{CDCl}_{3}\right): \delta 2.91(1 \mathrm{H}, \mathrm{m}, \mathrm{H}-1), 1.91(1 \mathrm{H}, \mathrm{m}, \mathrm{H}-2 \alpha), 1.85(1 \mathrm{H}, \mathrm{m}, \mathrm{H}-2 \beta), 2.14(1 \mathrm{H}, \mathrm{m}$, H-3 $), 2.5$ (2H, m, H-3), 2.87 (1H, m, H-5), 3.95 (1H, t, J = 10 Hz, H6), 2.90 (1H, m, H-7), 2.24 (1H, m, H-8 $\alpha), 1.42(1 \mathrm{H}, \mathrm{m}, \mathrm{H}-8 \beta), 2.48(1 \mathrm{H}, \mathrm{m}, \mathrm{H}-9 \alpha), 2.19(1 \mathrm{H}, \mathrm{m}, \mathrm{H}-9 \beta), 6.22(1 \mathrm{H}, \mathrm{d}, J=3.6 \mathrm{~Hz}, \mathrm{H}-13 \alpha), 5.47$ $(1 \mathrm{H}, \mathrm{d}, J=3.6, \mathrm{H}-13 \beta), 4.87(1 \mathrm{H}, \mathrm{s}, \mathrm{H}-14 \alpha), 4,79(1 \mathrm{H}, \mathrm{s}, \mathrm{H}-14 \beta), 5.25(1 \mathrm{H}, \mathrm{d}, J=2.4 \mathrm{~Hz}, \mathrm{H}-15 \alpha), 5.04$ $(1 \mathrm{H}, \mathrm{d}, J=2.4 \mathrm{~Hz}, \mathrm{H}-15 \beta) .{ }^{13} \mathrm{C}-\mathrm{NMR}\left(150 \mathrm{MHz}, \mathrm{CDCl}_{3}\right): \delta 30.2$ (C-3), 30.9 (C-8), $32.4(\mathrm{C}-2), 36.2(\mathrm{C}-9)$, 45.09 (C-1), 47.5 (C-7), 52.0 (C-5), 85.2 (C-6), 109.59 (C-14), 112.6 (C-15), 120.19 (C-13), 139.7 (C-11), 149.2 (C-10), 151.2 (C-4), 170.27(C-12). Comparing spectral data (Figures S6-S10) with reference data [12], the compound was confirmed as dehydrocostus lactone, an guaianolide sesquiterpene lactone (Figure 4c).

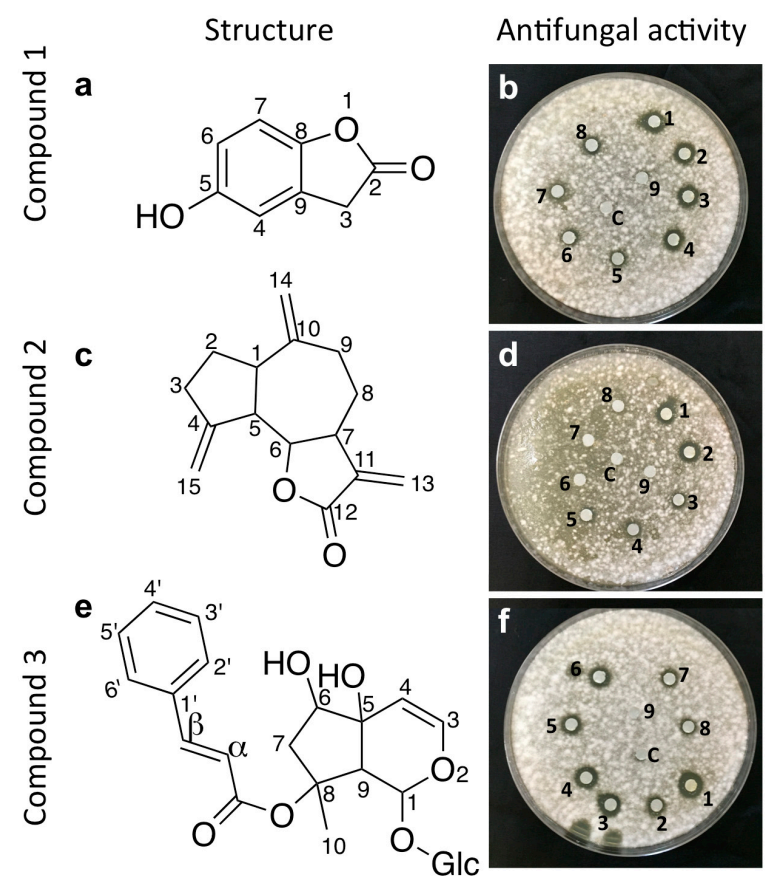

Figure 4. Structures and in vitro activity of the purified anti-Fusarium compounds from fungal endophyte strains WF5, WF6 and WF7. (a) Structure of compound 1,5-hydroxy benzofuranone (from strain WF5); (b) Representative picture of the disc diffusion assay showing the anti-Fusarium activity of compound 1; (c) Structure of compound 2, dehydrocostus lactone (from strain WF6); (d) Representative picture of the disc diffusion assay showing the anti-Fusarium activity of compound 2; (e) Structure of compound 3, harpagoside (from strain WF7); (f) Representative picture of the disc diffusion assay showing the anti-Fusarium activity of compound 3. Numbers (1-9) denote a concentration gradient of 4000, 2000, 1000, 500, 250, 125, 62.5, 31.25, 15.62 and $7.8 \mu \mathrm{g} / \mathrm{mL}$ while C denotes the solvent control.

\subsubsection{Compound 3 (Isolated from Fungus WF7)}

Compound 3 (molecular formula $\mathrm{C}_{24} \mathrm{H}_{30} \mathrm{O}_{11}$ ) was eluted from the $100 \%$ methanol fraction as an amorphous powder. The compound was further purified using preparative TLC with a mobile phase mixture of methanol-water (95:5), with an Rf value of 0.12 . The yield of compound 3 was $5 \mathrm{mg}$ from $3 \mathrm{~g}$ total extract. The IR and 1D-NMR data were as follows: IR: 3392, 2884, 1334, 1283, 989, $770 \mathrm{~cm}^{-1}$. ${ }^{1} \mathrm{H}-\mathrm{NMR}\left(600 \mathrm{MHz}_{\mathrm{CDCl}}\right.$ ): 1.33 (3H, s, H-10), $1.74(1 \mathrm{H}, \mathrm{dd}, J=14.5$ and $4 \mathrm{~Hz}, \mathrm{H}-7 \alpha), 2.15(1 \mathrm{H}, \mathrm{d}$, $J=14.5 \mathrm{~Hz}, \mathrm{H}-7 \beta), 2.93$ (1H, s, H-9), 3.36-3.84 (Glc-2-6), 4.6 (Glc-1), 3.98 (1H, d, J = $4 \mathrm{~Hz}, \mathrm{H}-6), 4.83$ (1H, $\mathrm{d}, J=8 \mathrm{~Hz}, \mathrm{H}-4), 6.1(1 \mathrm{H}, \mathrm{s}, \mathrm{H}-1), 6.36(1 \mathrm{H}, \mathrm{d}, J=6.4 \mathrm{~Hz}, \mathrm{H}-3), 6.38(1 \mathrm{H}, \mathrm{d}, J=16 \mathrm{~Hz}, \mathrm{H}-\alpha), 7.47(3 \mathrm{H}, \mathrm{m}$, $\left.\mathrm{H}^{\prime}-5^{\prime}\right), 7.55\left(2 \mathrm{H}, \mathrm{m}, \mathrm{H}-2^{\prime}\right.$ and $\left.6^{\prime}\right), 7.58(1 \mathrm{H}, \mathrm{d}, J=16 \mathrm{~Hz}, \mathrm{H}-\beta) .{ }^{13} \mathrm{C}-\mathrm{NMR}\left(150 \mathrm{MHz}, \mathrm{CDCl}_{3}\right): 94(\mathrm{C}-1)$, 143.4 (C-3), 104.7 (C-4), 72.7 (C- 5), 76.5 (C-6), 45.0 (C-7), 87.3 (C-8), 53.4 (C-9), 22.4 (C-10), 119 (C- $\alpha)$, $144.9(\mathrm{C}-\beta), 167.3(\mathrm{C}=\mathrm{O}), 134.2\left(\mathrm{C}-1^{\prime}\right), 128.8\left(\mathrm{C}-2^{\prime}\right), 128.2\left(\mathrm{C}-3^{\prime}\right), 130.3\left(\mathrm{C}-4^{\prime}\right), 128.2\left(\mathrm{C}-5^{\prime}\right), 128.8\left(\mathrm{C}-6^{\prime}\right)$, 
99.1 (Glc-1'), 72.7 (Glc-2), 75.9 (Glc-3), 71.70 (Glc-4), 75.9 (Glc-5), 61.8 (Glc-6). Comparing spectral data (Figures S11-S15) results to the literature [13], the compound was identified as harpagoside, an iridoide glycoside (Figure 4e).

2.4. Microscopic Examination of the Interaction Between Each Pure Antifungal Compound and F. graminearum in Vitro

To visualize the interaction between each pure compound and F. graminearum in vitro, light microscopy was used (Figure 5).

a

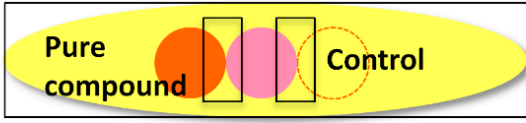

Fusarium

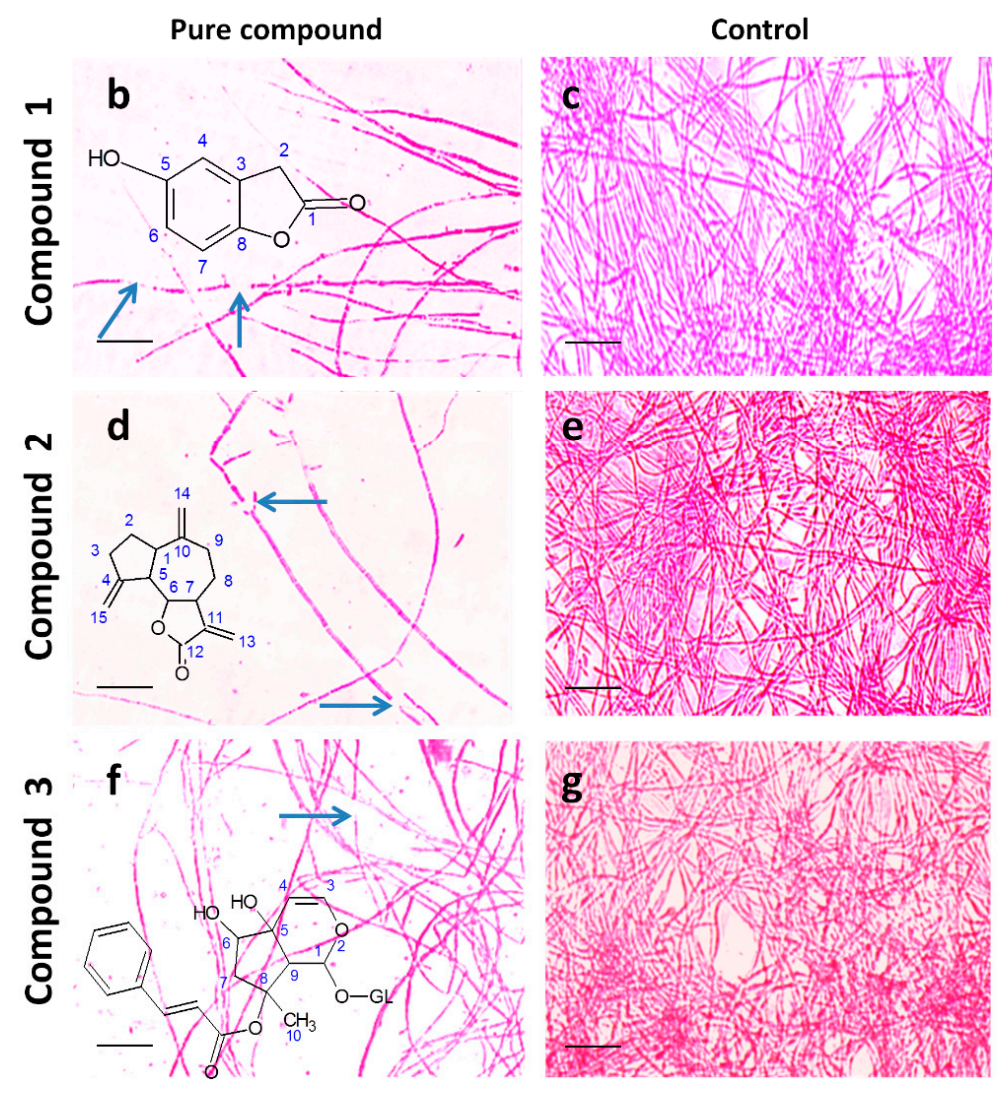

Figure 5. The effects of the purified endophyte-derived anti-fungal compounds on F. graminearum in vitro using neutral red staining. (a) Cartoon of the experimental methodology used to examine the in vitro interactions between F. graminearum (pink) and each compound (orange) or the buffer control (respective compound solvent). Microscope slides were pre-coated with PDA and incubated for $24 \mathrm{~h}$. F. graminearum hyphae were then stained with neutral red. Shown are representative microscope slide pictures $(n=3)$ of the interactions of $F$. graminearum with: (b) 5-hydroxy benzofuranone $(5 \mathrm{mg} / \mathrm{mL})$ compared to (c) the buffer control; (d) dehydrocostus lactone $(5 \mathrm{mg} / \mathrm{mL})$ compared to (e) the buffer control; (f) harpagoside $(5 \mathrm{mg} / \mathrm{mL}$ ) compared to (g) the buffer control. The blue arrows point to areas of apparent breakage of $F$. graminearum hyphae. Each scale bar equals $25 \mu \mathrm{m}$.

All compounds resulted in reduced hyphal growth associated with frequent hyphal breakage (Figure 5b,d,f), compared to the control (Figure 5c,e,g), suggestive of a mixed fungistatic/fungicidal mode of action. Interestingly, the hyphae of F. graminearum appeared to bend away from the contact zone with compounds 2 and 3 (Figure 5d,f). However, the effect of all purified compounds on 
F. graminearum hyphae was weak/moderate when compared to other antifungal compounds previously isolated from finger miller fungal endophytes [2].

\section{Discussion}

Endophytes are defined as microbes that are able to colonize the internal tissues of their host plants without causing disease [14]. We hypothesized that finger millet may host endophytes with anti-fungal activity, including against the pathogen Fusarium graminearum, because this crop is known to be resistant to many pathogens including F. graminearum [2,3,5], and its endophytes may have co-evolved with Fusarium pathogens in Africa [15,16] and South Asia [17,18]. In a previous study [2], we identified four distinct, putative, fungal endophyte species from finger millet (WF4-7). The putative endophytes were isolated from plants of first generation seeds, and then grown on Turface clay rock using hydroponics rather than on soil. This growth system may have contributed to the low abundance and biodiversity of the isolated endophytes.

In our earlier study [2], we showed that extracts of the putative endophytes have antifungal activities including against $F$. graminearum. Only the extract from WF4, a Phoma sp. was characterized in detail, and revealed four anti-Fusarium compounds (viridicatol, tenuazonic acid, alteraniol and alteraniol methyl ether). Here, we confirmed that these fungal strains are able to re-colonize the internal tissues of the host without causing pathogenic symptoms, when compared to the known pathogen Alternaria alternate, consistent with their classification as endophytes. We identified the compounds underlying the antifungal activity of these endophytes alongside a suggested mode of action. The current anti-Fusarium compounds are different than those previously identified and broaden the range of bio-fungicides identified from the finger millet microbiome against this important crop pathogen.

\subsection{Previous Reports of Non-Pathogenic Fusarium and Penicillium sp. as Endophytes}

One fungal strain reported in this study was predicted to be a Fusarium sp. (WF5). Previous studies involving Fusarium and Aspergillus sp. have shown that non-pathogenic fungal strains that belong to the same species as a pathogen can, in some cases, control the ability of the pathogen to cause disease and produce mycotoxins $[19,20]$. Several competitive exclusion mechanisms have been suggested that explain the biological control ability [21]. These mechanisms include blockage of infection sites, competition for limited nutrients in the soil, inhibition of spore germination and induction of host resistance [22,23]. In the current study, we showed that the ability of non-pathogenic Fusarium sp. to control pathogenic Fusarium sp. may also be mediated by production of antifungal secondary metabolites.

The two other fungal strains (WF6 and WF7) characterized in this study were closely related to Penicillium sp., including one that most closely resembled Penicillium chrysogenum (WF6) taxonomically. P. chrysogenum was previously isolated as an endophyte of marine red algal species of the genus Laurencia, and was reported to have antifungal activity against the fungus Alternaria brassicae. The antifungal metabolite was identified to be a mono-terpene derivative [24]. This observation is of interest because the anti-Fusarium compound that we purified from the apparent $P$. chrysogenum isolate from finger millet is a sesquiterpene lactone, suggesting that the terpenoid pathway may play an important role in the anti-pathogenesis of P. chrysogenum endophytes. Other Penicillium sp. were isolated from diverse hosts including the South Asian medicinal plant Ocimum tenuiflorum [25], the Moroccan plant Ceratonia siliqua [26], Cannabis sativa L. [27] and Panax ginseng [28]. An extract from the Penicillium isolate of Panax ginseng showed anti-fungal activity against Pyricularia oryzae [28]. We emphasize this last observation because $P$. oryzae is the most important fungal pathogen of finger millet, the causal agent of blast disease [29]. 


\subsection{Anti-Fusarium Compounds Purified from Finger Millet Endophytes}

Here, we have elucidated the structures of three active anti-Fusarium compounds: 5-hydroxy benzofuranone, dehydrocostus lactone, and an iridoide glycoside (harpagoside) (Figure 4).

\subsubsection{4-Hydroxybenzofuranone (Isolated from Fusarium sp. Strain WF5)}

Simple benzofuranone derivatives have previously been isolated from fungi including Coniothyrium minitans [30]. Other conjugated benzofuranones have been reported from endophytic fungi such as Pestalotiopsis photiniae, an endophyte that inhabits the Chinese plant, Roystonea regia [31]. Some benzofuranone derivatives were reported to have algicidal, hypotensive and anti-inflammatory activities [32,33]. To the best of our knowledge, this is the first report of 4-hydroxy- benzofuranone having anti-Fusarium activity.

\subsubsection{Dehydrocostus Lactone (Isolated from Penicillium sp. Strain WF6)}

Dehydrocostus lactone derivatives were previously isolated from plant species including Inula racemosa, Centaurea pannonica and Saussurea costus [34-36]. The compound was reported to have antimicrobial activity including against Mycobacterium sp., Propionibacterium acnes, Staphylococcus aureus, and Malassezia furfur [36,37]. Dehydrocostus lactone was reported to have multiple biological activities including suppression of melanin production, induction of apoptosis in soft tissue sarcoma cell lines, inhibition of migration of prostate cancer cells and anti-trypanosoma activity $[35,36,38,39]$. To the best of our knowledge, this is the first report of dehydrocostus lactone from a fungal source and the first report of it having anti-Fusarium activity.

\subsubsection{Harpagoside (Isolated from Penicillium sp. Strain WF7)}

Harpagoside was first isolated from Harpagophytum procumbens (Devil's claw), a plant widely used in folk medicine for its anti-microbial, anti-inflammatory and analgesic properties [40]. Subsequently, harpagoside was identified in diverse plants including Radix scrophulariae, a plant used as an herbal medicine for treatment of congestion, constipation and sore throats [41]. Harpagoside was reported to have anti-inflammatory, antioxidant and analgesic properties [42] To the best of our knowledge, this is the first report of dehydrocostus lactone from a fungal source and the first report of it having anti-Fusarium activity.

\section{Experimental Section}

\subsection{Source of Biological Materials}

Putative fungal endophyte strain WF5 (Fusarium sp.) was previously from finger millet shoots (Genbank: KF957640) using a previously described protocol (Figure 1) [2]. Putative fungal endophyte strains WF6 and WF7 (Penicillium sp.) were previously isolated from finger millet roots (Genbank: KF957641 and KF957642) (Figure 1) [2]. In brief, commercial finger millet seeds originating from India were germinated and grown in pails of Turface clay placed in the field (Arkell Field Station, Arkell, ON, Canada, GPS: $43^{\circ} 39^{\prime} \mathrm{N}, 80^{\circ} 25^{\prime} \mathrm{W}$, and $375 \mathrm{~m}$ above sea level). At the pre-flowering stage, five samples were collected from seeds, intact roots and shoots. The entire sampling was repeated three times independently. Samples were surface sterilized according to a standard protocol [2]. Sterilized tissues were ground in LB liquid medium and the extracts were plated onto Potato Dextrose Agar (PDA). Fungi with unique morphology were collected and re-cultured on fresh media for purity.

The F. graminearum strain used in this study (15 Acetyl DON Producer) was obtained from the Agriculture and Agrifood Canada Fungal Type Culture Collection (AAFC Food Research Centre, Guelph, ON, Canada). The effect of the crude culture extract of each fungus on the growth of F. graminearum was previously shown (Figure 1) [2]. 


\subsection{Competitive Inhibition Experiment}

To test the ability of each endophytic strain to competitively inhibit the growth of $F$. graminearum, co-incubation experiments were conducted. Each fungus was grown on PDA plates at $25{ }^{\circ} \mathrm{C}$ for one week. Thereafter, $5 \mathrm{~mm}$ agar plugs from each endophytic fungus were inoculated near the edge of fresh PDA plates, and $5 \mathrm{~mm}$ agar plugs of $F$. graminearum were inoculated on the other edge. Both F. graminearum and each endophytic fungus were co-incubated at $25^{\circ} \mathrm{C}$ for two weeks. There were three replicates for each endophytic strain.

\subsection{Plant Pathogenicity Assay}

To confirm that the putative fungal endophytes are not pathogens, a plant pathogenesis assay was conducted. Seeds of finger millet were surface sterilized by washing in $0.1 \%$ Triton X-100 detergent $(10 \mathrm{~min})$, followed by $3 \%$ sodium hypochlorite $(20 \mathrm{~min}$, twice). Seeds were planted on sterile Phytagel based medium consisted of: 1 package Murashige and Skoog modified basal salt mixture (Catalog \#M571, PhytoTechnology Laboratories, Shawnee Mission, KS, USA), 4 g Phytagel, $1 \mathrm{~mL}$ pyridoxine $\mathrm{HCl}(0.5 \mathrm{mg} / \mathrm{mL}), 500 \mu \mathrm{L}$ nicotinic acid $(1 \mathrm{mg} / \mathrm{mL}), 0.332 \mathrm{~g} \mathrm{CaCl}_{2}, 1 \mathrm{~mL}$ glycine ( $2 \mathrm{mg} / \mathrm{mL}), 10 \mathrm{~mL}$ thiamine $\mathrm{HCl}(100 \mathrm{mg} / \mathrm{L})$, and $1 \mathrm{~mL} \mathrm{MgSO}_{4}(18 \mathrm{~g} / 100 \mathrm{~mL})$, per liter. The medium was distributed into sterile glass tubes. Seven seeds were transferred to each tube and allowed to germinate in the dark for seven days, then transferred to light shelves $\left(25^{\circ} \mathrm{C}, 16 \mathrm{~h}\right.$ light $)$. When seedlings were one week old, each endophyte (or control) was applied onto the gel surface $(11 \mathrm{~mm}$ diameter agar discs), in triplicate. Seedlings that were not inoculated with any fungi served as the negative control. Seedlings that were infected with the fungal pathogen Alternaria alternata were the positive control [43]. Plants were then assessed visually for disease symptoms at 10 days after inoculation with each endophyte or control pathogen. Then, the percentage surface area that showed lesions was quantified using Assess Software (Version 2.0, American Phytopathological Society, St. Paul, MN, USA) in comparison to controls. Results were statistically analyzed using Prism software version 5 (GraphPad Software Inc., La Jolla, CA, USA).

\subsection{Root Colonization Assay}

To test if the putative endophytes are able to colonize the roots of finger millet, confocal microscopy imaging was conducted. Finger millet seeds were surface sterilized and planted in glass tubes containing sterile Phytagel based medium (as described above). Each fungal endophyte was applied, in triplicate ( $100 \mu \mathrm{L}$ of a $48 \mathrm{~h}$ old culture grown in potato dextrose medium) to finger millet seedlings (17 days after germination) and co-incubated with the seedlings at room temperature. The control consisted of finger millet seedlings incubated with potato dextrose medium only. Calcofluor white stain was used to stain fungi (catalogue \#18909, Sigma Aldrich, St. Louis, MO, USA), following the manufacturer's protocol. Thereafter, finger millet roots were scanned with a Leica TCS SP5 confocal laser scanning microscope (Leica Microsystems, Wetzlar, Germany) at the Molecular and Cellular Imaging Facility, University of Guelph.

\subsection{Bio-Guided Purification of Active Anti-Fusarium Compounds}

For large scale fermentation, each endophyte was fermented in $2 \mathrm{~L}$ flasks (five flasks per each endophyte) containing $50 \mathrm{~g}$ white rice and $100 \mathrm{~mL} \mathrm{H}_{2} \mathrm{O}$. The flasks were incubated at $25^{\circ} \mathrm{C}$ for 30 days without shaking (Figure $1 \mathrm{f}-\mathrm{h}$ ). Then, each culture was extracted with ethyl acetate, and washed with water to remove salts and sugars. The extract was dried under vacuum at $45{ }^{\circ} \mathrm{C}$ and subjected to fractionation between methanol and $n$-hexane phases to remove long chain fatty acids. To purify the active compounds, the dry residues were separated by flash liquid chromatography. The column was filled with flash grade silica gel (SiliaFlash ${ }^{\circledR}$ P60 230-400, SiliCycle, Quebec City, QC, Canada, Catalog \# R12030B) and saturated with the desired mobile phase just prior to sample loading. For each endophyte, $3 \mathrm{~g}$ of the dry residue extract was dissolved in chloroform, mixed with silica and evaporated 
under vacuum. The extract was applied as a dried silica band on top of the column. The mobile phase (gradient combination of hexane/ethyl acetate followed by ethyl acetate/methanol) was then passed through the column under air pressure. Thin layer chromatography (TLC) was used to visualize the bands using different solvent-system combinations and vanillin- $\mathrm{H}_{2} \mathrm{SO}_{4}$ reagent. Eluted fractions were tested for anti-Fusarium activity using the dual culture agar diffusion method (as described below). Candidate fractions that inhibited the growth of $F$. graminearum were subjected to further purification using flash column chromatography and/or preparative TLC. Purified compounds were re-screened for inhibition of $F$. graminearum growth using disc diffusion assay. The active compounds were subjected to further spectroscopic structural elucidation.

\subsection{Antifungal Assay of Purified Compounds Using Agar Diffusion Assay}

To enable the bio-guided purification, the dual culture agar diffusion assay was employed. F. graminearum was grown for $48 \mathrm{~h}\left(25^{\circ} \mathrm{C}, 100 \mathrm{rpm}\right)$ in liquid potato dextrose broth (Catalog \# P6685, Sigma Aldrich), then mycelia were added to melted and cooled PDA media ( $1 \mathrm{~mL}$ of fungal culture into $100 \mathrm{~mL}$ of media), mixed and poured into Petri dishes $(100 \mathrm{~mm} \times 15 \mathrm{~mm})$, then allowed to re-solidify. Wells (11 mm diameter) were created in this pathogen-embedded agar by puncturing with sterile glass tubes, then a fraction/compound was applied into each well (100 $\mu \mathrm{L}$ per well) in triplicate. The agar plates were incubated at $25^{\circ} \mathrm{C}$ for $48 \mathrm{~h}$. The diameter of each zone of inhibition was measured $(\mathrm{mm})$. Appropriate solvent mixtures were used as negative controls. Nystatin fungicide (Catalog \#N6261, Sigma Aldrich) was used as a positive control at a concentration of $10 \mu \mathrm{g} / \mathrm{mL}$.

\subsection{Structure Elucidation of Active Anti-F. graminearum Compounds}

Each purified compound was structurally elucidated using one and two dimensional nuclear magnetic resonance (NMR) techniques in combination with mass spectrometry (MS) methods and IR (infra-red) spectroscopy. NMR analyses were conducted at the University of Guelph-NMR Facility using a $600 \mathrm{DPX}$ spectrometer (Bruker, Karlsuhe, Germany) operating at $600 \mathrm{MHz}$ for ${ }^{1} \mathrm{H}$ and 150 for ${ }^{13} \mathrm{C}$. Structural assignments were based on spectra resulting from the following NMR experiments: ${ }^{1} \mathrm{H},{ }^{13} \mathrm{C},{ }^{1} \mathrm{H}-{ }^{1} \mathrm{H}$ COSY,${ }^{1} \mathrm{H}_{-}{ }^{13} \mathrm{C}$ direct correlation (HSQC), ${ }^{1} \mathrm{H}_{-}{ }^{13} \mathrm{C}$ long-range correlation (HMBC). IR spectroscopy was conducted using a Bruker Alpha IR Spectrometer instrument (Bruker, Karlsuhe, Germany) located in the Department of Chemistry, University of Guelph. MS was conducted in the Mass Spectroscopy Facility of the Advanced Analysis Centre of the University of Guelph using an Agilent LC-UHD Q-Tof (Agilent Technologies, Santa Clara, CA, USA) with the following acquisition parameters: Ion Source (ESI), Ion Polarity (Positive), capillary exit (Resolution, 140.0 V), Trap Drive (58.9 arbitrary units), Accumulation Time (1348 $\mu$ s), Averages (3 Spectra).

\subsection{Visualization of the Interactions Between F. graminearum and the Anti-F. graminearum Compounds}

To visualize the interactions between F. graminearum and each pure anti-F. graminearum compound, light microscopy was used combined with vitality staining. Microscope slides were coated with a thin layer of PDA, then $100 \mu \mathrm{L}$ of $F$. graminearum culture ( $48 \mathrm{~h}$ old grown in potato dextrose broth at $25{ }^{\circ} \mathrm{C}$, with shaking at $100 \mathrm{rpm}$ ) were applied adjacent to $20 \mu \mathrm{L}$ of each purified compound $(5 \mathrm{mg} / \mathrm{mL})$. There were three replicates for each slide. Slides were incubated at $25^{\circ} \mathrm{C}$ for $24 \mathrm{~h}$, stained with $100 \mu \mathrm{L}$ of neutral red (Sigma Aldrich, Catalog \#57993) for 3-5 min, then washed 3-4 times with de-ionized water. Images were taken using an MZ8 microscope (Leica Microsystems, Wetzlar, Germany).

\section{Conclusions and Future Perspectives}

A growing number of reports in the literature suggest that endophytic microbes may produce secondary metabolites that are also produced in parallel by their host plants [44-46]. Here, we reported the ability of endophytic fungi to produce small bioactive molecules previously reported as plant metabolites. It will be interesting to conduct future experiments to elucidate whether these apparent plant-derived compounds are in fact derived from their microbial inhabitants either exclusively or 
additively. It would be interesting to study the ability of each endophyte to inhibit the pathogen in finger millet and to test the pathogen specificity of each endophyte and its metabolite(s). As a general lesson, this study highlights the value of exploring the orphan crops of subsistence farmers as sources of endophytes and antifungal compounds with potential to combat serious pathogens afflicting mainstream, global agriculture.

Supplementary Materials: Supplementary materials can be accessed at: http://www.mdpi.com/1420-3049/21/ 9/1171/s1.

Acknowledgments: W.K.M. was supported by generous scholarships from the Government of Egypt, the University of Guelph International Graduate Student Scholarship $(2012,2014)$. This research was supported by grants to M.N.R. by the Ontario Ministry of Agriculture and Food (OMAF), Grain Farmers of Ontario (GFO) and the Canadian International Development Research Centre (IDRC) and Global Affairs Canada as part of the CIFSRF program.

Author Contributions: W.K.M. performed all experiments, analyzed data and wrote the manuscript. A.L.S. contributed chemicals and help in structural elucidation of the compounds. M.N.R. helped in designing the experiments, interpreting the data and writing of the manuscript.

Conflicts of Interest: The authors declare no conflict of interest.

\section{References}

1. Hilu, K.W.; Wet, J.M.J.D. Domestication of Eleusine coracana. Econ. Bot. 1976, 30, 199-208. [CrossRef]

2. Mousa, W.K.; Schwan, A.; Davidson, J.; Strange, P.; Liu, H.; Zhou, T.; Auzanneau, F.-I.; Raizada, M.N. An endophytic fungus isolated from finger millet (Eleusine coracana) produces anti-fungal natural products. Front. Microbiol. 2015, 6, 1157. [CrossRef] [PubMed]

3. Munimbazi, C.; Bullerman, L.B. Molds and mycotoxins in foods from burundi. J. Food Prot. 1996, 59, 869-875.

4. Van der Lee, T.; Zhang, H.; van Diepeningen, A.; Waalwijk, C. Biogeography of Fusarium graminearum species complex and chemotypes. Food Add. Contam. 2015, 32, 453-460. [CrossRef] [PubMed]

5. Sundaramari, M. Rationality and adoption of indigenous cultivation practices of finger millet (Eleusine coracana (L.)gaertn.) by the tribal farmers of tamil nadu. Int. J. Mang. Soc. Sci. 2015, 2, 970-977.

6. Wegulo, S.N.; Baenziger, P.S.; Nopsa, J.H.; Bockus, W.W.; Hallen-Adams, H. Management of Fusarium head blight of wheat and barley. Crop Prot. 2015, 73, 100-107. [CrossRef]

7. Wong, L.; Abramson, D.; Tekauz, A.; Leisle, D.; McKenzie, R. Pathogenicity and mycotoxin production of Fusarium species causing head blight in wheat cultivars varying in resistance. Can. J. Plant Sci. 1995, 75, 261-267. [CrossRef]

8. O'Donnell, K.; Rooney, A.P.; Proctor, R.H.; Brown, D.W.; McCormick, S.P.; Ward, T.J.; Frandsen, R.J.N.; Lysøe, E.; Rehner, S.A.; Aoki, T.; et al. Phylogenetic analyses of RPB1 and RPB2 support a middle cretaceous origin for a clade comprising all agriculturally and medically important fusaria. Fungal Genet. Biol. 2013, 52, 20-31. [CrossRef] [PubMed]

9. Mousa, W.K.; Shearer, C.R.; Limay-Rios, V.; Zhou, T.; Raizada, M.N. Bacterial endophytes from wild maize suppress Fusarium graminearum in modern maize and inhibit mycotoxin accumulation. Front. Plant Sci. 2015, 6, 805. [CrossRef] [PubMed]

10. Shehata, H.R.; Lyons, E.M.; Jordan, K.S.; Raizada, M.N. Bacterial endophytes from wild and ancient maize are able to suppress the fungal pathogen Sclerotinia homoeocarpa. J. Appl. Microbiol. 2016, 120, 56-69. [CrossRef] [PubMed]

11. Venkateswarlu, S.; Panchagnula, G.K.; Guraiah, M.B.; Subbaraju, G.V. Isoaurones: Synthesis and stereochemical assignments of geometrical isomers. Tetrahedron 2006, 62, 9855-9860. [CrossRef]

12. Yuuya, S.; Hagiwara, H.; Suzuki, T.; Ando, M.; Yamada, A.; Suda, K.; Kataoka, T.; Nagai, K. Guaianolides as immunomodulators. Synthesis and biological activities of dehydrocostus lactone, mokko lactone, eremanthin, and their derivatives. J. Nat. Prod. 1998, 62, 22-30. [CrossRef] [PubMed]

13. Tong, S.; Yan, J.; Lou, J. Preparative isolation and purification of harpagoside from Scrophularia ningpoensis hemsley by high-speed counter-current chromatography. Phytochem. Anal. 2006, 17, 406-408. [CrossRef] [PubMed]

14. Wilson, D. Endophyte: The evolution of a term, and clarification of its use and definition. Oikos 1995, 73, 274-276. 
15. Saleh, A.A.; Esele, J.; Logrieco, A.; Ritieni, A.; Leslie, J.F. Fusarium verticillioides from finger millet in Uganda. Food Add. Contam. 2012, 29, 1762-1769. [CrossRef] [PubMed]

16. Adipala, E. Seed-borne fungi of finger millet. E. Afr. Agric. Forest J. 1992, 57, 173-176.

17. Penugonda, S.; Girisham, S.; Reddy, S. Elaboration of mycotoxins by seed-borne fungi of finger millet (Eleusine coracana L.). Int. J. Biotechnol. Mol. Biol. Res. 2010, 1, 62-64.

18. Ramana, M.V.; Nayaka, S.C.; Balakrishna, K.; Murali, H.; Batra, H. A novel PCR-DNA probe for the detection of fumonisin-producing Fusarium species from major food crops grown in southern India. Mycology 2012, 3, 167-174.

19. Cooney, J.M.; Lauren, D.R.; di Menna, M.E. Impact of competitive fungi on trichothecene production by Fusarium graminearum. J. Agric. Food Chem. 2001, 49, 522-526. [CrossRef] [PubMed]

20. Cotty, P.J. Biocompetitive exclusion of toxigenic fungi. In The Mycotoxin Factbook Food and Feed Topics; Barug, D., Bhatnagar, D., van Egmond, H.P., van der Kamp, J.W., van Osenbruggen, W.A., Visconti, A., Eds.; Wageningen Academic Publishers: Wageningen, The Netherlands, 2006; pp. 179-197.

21. Dawson, W.; Jestoi, M.; Rizzo, A.; Nicholson, P.; Bateman, G. Field evaluation of fungal competitors of Fusarium culmorum and F. graminearum, causal agents of ear blight of winter wheat, for the control of mycotoxin production in grain. Biocontrol Sci. Technol. 2004, 14, 783-799. [CrossRef]

22. Fravel, D.; Olivain, C.; Alabouvette, C. Fusarium oxysporum and its biocontrol. New Phytol. 2003, 157, 493-502. [CrossRef]

23. Larkin, R.P.; Fravel, D.R. Mechanisms of action and dose-response relationships governing biological control of fusarium wilt of tomato by nonpathogenic Fusarium spp. Phytopathology 1999, 89, 1152-1161. [CrossRef] [PubMed]

24. Gao, S.-S.; Li, X.-M.; Du, F.-Y.; Li, C.-S.; Proksch, P.; Wang, B.-G. Secondary metabolites from a marine-derived endophytic fungus Penicillium chrysogenum qen-24s. Mar. Drugs 2010, 9, 59-70. [CrossRef] [PubMed]

25. Lai, D.; Brotz-Oesterhelt, H.; Muller, W.E.G.; Wray, V.; Proksch, P. Bioactive polyketides and alkaloids from Penicillium citrinum, a fungal endophyte isolated from Ocimum tenuiflorum. Fitoterapia 2013, 91, 100-106. [CrossRef] [PubMed]

26. El-Neketi, M.; Ebrahim, W.; Lin, W.H.; Gedara, S.; Badria, F.; Saad, H.E.A.; Lai, D.W.; Proksch, P. Alkaloids and polyketides from penicillium citrinum, an endophyte isolated from the Moroccan plant Ceratonia siliqua. J. Nat. Prod. 2013, 76, 1099-1104. [CrossRef] [PubMed]

27. Kusari, P.; Kusari, S.; Spiteller, M.; Kayser, O. Endophytic fungi harbored in Cannabis sativa L.: Diversity and potential as biocontrol agents against host plant-specific phytopathogens. Fungal Divers. 2013, 60, 137-151. [CrossRef]

28. Zheng, C.J.; Xu, L.L.; Li, Y.Y.; Han, T.; Zhang, Q.Y.; Ming, Q.L.; Rahman, K.; Qin, L.P. Cytotoxic metabolites from the cultures of endophytic fungi from Panax ginseng. Appl. Microbiol. Biotechnol. 2013, 97, 7617-7625. [CrossRef] [PubMed]

29. Lenné, J.; Takan, J.; Mgonja, M.; Manyasa, E.; Kaloki, P.; Wanyera, N.; Okwadi, J.; Muthumeenakshi, S.; Brown, A.; Tamale, M. Finger millet blast disease management: A key entry point for fighting malnutrition and poverty in East Africa. Outlook Agric. 2007, 36, 101-108. [CrossRef]

30. Machida, K.; Trifonov, L.S.; Ayer, W.A.; Lu, Z.-X.; Laroche, A.; Huang, H.C.; Cheng, K.J.; Zantige, J.L. 3(2h)-benzofuranones and chromanes from liquid cultures of the mycoparasitic fungus Coniothyrium minitans. Phytochemistry 2001, 58, 173-177. [CrossRef]

31. Ding, G.; Zheng, Z.; Liu, S.; Zhang, H.; Guo, L.; Che, Y. Photinides a-f, cytotoxic benzofuranone-derived $\gamma$-lactones from the plant endophytic fungus pestalotiopsis photiniae. J. Nat. Prod. 2009, 72, 942-945. [CrossRef] [PubMed]

32. Yang, W.; Liu, Y.; Liu, J.; Liu, Z. Inhibitory effects and chemical basis of eucalyptus orelliana wood meals on the growth of Alexandrium tamarense. Huan Jing Ke Xue 2008, 29, 2296-2301. [PubMed]

33. De Souza Nunes, J.P.; da Silva, K.A.B.; da Silva, G.F.; Quintão, N.L.M.; Corrêa, R.; Cechinel-Filho, V.; de Campos-Buzzi, F.; Niero, R. The antihypersensitive and antiinflammatory activities of a benzofuranone derivative in different experimental models in mice: The importance of the protein kinase c pathway. Anesth. Analg. 2014, 119, 836-846. [CrossRef] [PubMed]

34. Milošević Ifantis, T.; Solujić, S.; Pavlović-Muratspahić, D.; Skaltsa, H. Secondary metabolites from the aerial parts of Centaurea pannonica (Heuff.) simonk. From Serbia and their chemotaxonomic importance. Phytochemistry 2013, 94, 159-170. [CrossRef] [PubMed] 
35. Julianti, T.; Hata, Y.; Zimmermann, S.; Kaiser, M.; Hamburger, M.; Adams, M. Antitrypanosomal sesquiterpene lactones from Saussurea costus. Fitoterapia 2011, 82, 955-959. [CrossRef] [PubMed]

36. Rao, G.V.; Reddy, M.V.B.; Pirabakaran, R.; Madhavi, M.S.L.; Kavitha, K.; Mukhopadhyay, T. Antimicrobial and melanin synthesis inhibitory activities of the roots of Inula racemosa hook f. Arch. Appl. Sci. Res. 2013, 5, 104-108.

37. Cantrell, C.L.; Nuñez, I.S.; Castañeda-Acosta, J.; Foroozesh, M.; Fronczek, F.R.; Fischer, N.H.; Franzblau, S.G. Antimycobacterial activities of dehydrocostus lactone and its oxidation products. J. Nat. Prod. 1998, 61, 1181-1186. [CrossRef] [PubMed]

38. Kretschmer, N.; Rinner, B.; Stuendl, N.; Kaltenegger, H.; Wolf, E.; Kunert, O.; Boechzelt, H.; Leithner, A.; Bauer, R.; Lohberger, B. Effect of costunolide and dehydrocostus lactone on cell cycle, apoptosis, and abc transporter expression in human soft tissue sarcoma cells. Planta Med. 2012, 78, 1749-1756. [CrossRef] [PubMed]

39. Kim, E.J.; Hong, J.E.; Lim, S.S.; Kwon, G.T.; Kim, J.; Kim, J.-S.; Lee, K.W.; Park, J.H.Y. The hexane extract of Saussurea lappa and its active principle, dehydrocostus lactone, inhibit prostate cancer cell migration. J. Med. Food 2012, 15, 24-32. [CrossRef] [PubMed]

40. Mncwangi, N.; Chen, W.; Vermaak, I.; Viljoen, A.M.; Gericke, N. Devil's claw-A review of the ethnobotany, phytochemistry and biological activity of Harpagophytum procumbens. J. Ethnopharmacol. 2012, 143, 755-771. [CrossRef] [PubMed]

41. Li, P.; Zhang, Y.; Xiao, L.; Jin, X.; Yang, K. Simultaneous determination of harpagoside and cinnamic acid in rat plasma by high-performance liquid chromatography: Application to a pharmacokinetic study. Anal. Bioanal. Chem. 2007, 389, 2259-2264. [CrossRef] [PubMed]

42. Georgiev, M.I.; Ivanovska, N.; Alipieva, K.; Dimitrova, P.; Verpoorte, R. Harpagoside: From Kalahari Desert to pharmacy shelf. Phytochemistry 2013, 92, 8-15. [CrossRef] [PubMed]

43. Kumar, B. Phytotoxic effect of seed mycoflora associated with the genotypes of finger millet (Eleusine coracana). Prog. Agric. 2010, 10, 112-115.

44. Hussain, H.; Krohn, K.; Ullah, Z.; Draeger, S.; Schulz, B. Bioactive chemical constituents of two endophytic fungi. Biochem. Syst. Ecol. 2007, 35, 898-900. [CrossRef]

45. Soliman, S.S.; Greenwood, J.S.; Bombarely, A.; Mueller, L.A.; Tsao, R.; Mosser, D.D.; Raizada, M.N. An endophyte constructs fungicide-containing extracellular barriers for its host plant. Curr. Biol. 2015, 25, 2570-2576. [CrossRef] [PubMed]

46. Waqas, M.; Khan, A.L.; Kamran, M.; Hamayun, M.; Kang, S.-M.; Kim, Y.-H.; Lee, I.-J. Endophytic fungi produce gibberellins and indoleacetic acid and promotes host-plant growth during stress. Molecules 2012, 17, 10754-10773. [CrossRef] [PubMed]

Sample Availability: Trace samples of the compounds $\mathbf{1}$ and $\mathbf{2}$ are available from the authors.

(C) 2016 by the authors; licensee MDPI, Basel, Switzerland. This article is an open access article distributed under the terms and conditions of the Creative Commons Attribution (CC-BY) license (http://creativecommons.org/licenses/by/4.0/). 